QRU 1 / 151 
Estanislao ROCA

This article presents a reflection on university campus and its relationship with the city, through topics and invariants of settlement patterns and paradigmatic cases. Campus set different situations and ways of urban relationship, from urban location of early european models, to suburban locations of anglo-saxon models.

The article continues with a summary of professional and academic experience of Campus Diagonal in Barcelona, where the author drafted a development plan. The objective of this plan is: to revitalize the campus and to link the city through integration strategies with the surrounding tissue, incorporating complementary uses to the students. This campus belongs to the University of Barcelona (UB) and the Polytechnic University of Catalonia (UPC), which were presented together under the identification of "Knowledge Campus Barcelona. BKC". It was also presented at the Campus of Excellence, opened by the Ministries of Education and Science and Innovation in Spain, earning a prestigious distinction in November 2009.

The article presents the most relevant aspects of urban and architectural proposals of BKC, which is a " cluster" of first-class training and reference. It also has the highest concentration of knowledge in southern Europe, and novel and innovative teaching projects.

Key words: Urban planning, university campus 


\section{CAMPUS UNIVERSITARIO Y SU COMPROMISO URBANO}

Estanislao ROCA

El presente artículo presenta una reflexión sobre campus universitarios y su relación con la ciudad a través de tópicos e invariantes de modelos de asentamiento y casos paradigmáticos, donde se establecen distintas situaciones y maneras de relación urbana, desde los modelos europeos iniciales, de localización más nítidamente urbana, a modelos anglosajones con localizaciones periurbanas.

Continúa con un resumen de la experiencia profesional y académica en el Campus de la Diagonal de Barcelona, donde el autor redactó un plan urbanístico con el objetivo de vitalizar el campus e integrarlo a la ciudad a través de estrategias de conjunción con el tejido circundante, incorporando usos complementarios a los universitarios. Este campus está formado por la Universidad de Barcelona y la Universidad Politécnica de Cataluña que se presentaron conjuntamente bajo la identificación de "Barcelona Knowledge Campus. BKC" en la convocatoria de Campus de Excelencia Internacional abierta por los Ministerios de Educación y Ciencia e Innovación de España y obtuvieron la prestigiosa distinción en noviembre de 2009.

Se exponen los aspectos más relevantes de las propuestas urbanísticas y arquitectónicas del BKC que constituye un "cluster" de formación de primer orden y referencia, y cuenta con la mayor concentración de conocimiento del Sur de Europa y con novedosos proyectos docentes y de innovación.

Palabras clave: Planificación urbana, campus universitario 


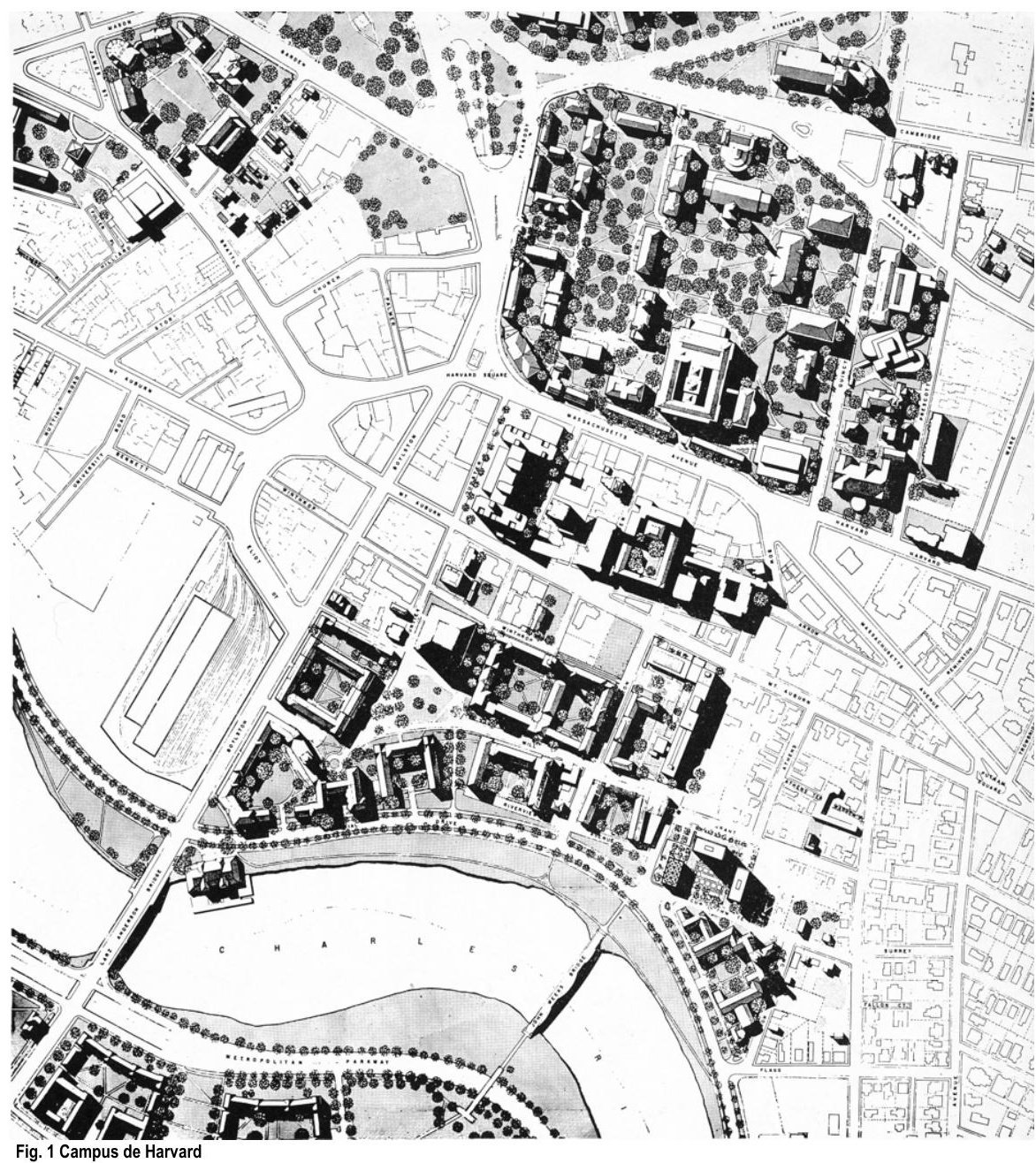




\section{INTRODUCCIÓN}

Apenas hace tres años que finalicé junto a Andrés Lezcano y Ricard Fayos la redacción del libro "Campus de la Diagonal. Un projecte urbă"1 publicado por la Universidad de Barcelona y le pasamos los textos al profesor y amigo Carlos Martí Arís para recabar su opinión. Tras mostrar su interés, le pedimos un prólogo que generosamente me remitió con el título "El Campus como principio urbano".

En él nos desvela desde la etimología que la evidente raíz de "campus" no es otra que el vocablo latín que alude al campo como término opuesto al de ciudad y aduce que la noción moderna de "campus" reclamaría como objetivos principales el retorno de la presencia activa de la naturaleza dentro del tejido urbano y el reencuentro de un nuevo equilibrio entre ambos factores vistos como ingredientes básicos del espacio habitable.

Y añade que aún hay un principio urbano de carácter más general en la noción de "campus", que algunos ejemplos de arquitectura moderna han sabido desarrollar. Es la radical inversión de tejido estructural, propio de la ciudad actual, que se produce en aceptar la forma convexa y aislada de los edificios, la cual hace que el espacio público se genere a través de un juego de relaciones que los edificios establecen entre sí. De forma que la edificación ya no es un sólido continuo donde los espacios libres son figuras recortadas en la masa continua sino que es el vacio continuo del espacio libre, el que asume el rol de trama de fondo sobre el cual se disponen las figuras autónomas de los edificios.

Esta línea de trabajo permite que el análisis y el proyecto de un campus universitario se convierta, de forma natural, en laboratorio de ensayos sobre la multiplicidad de formas que puede adoptar la ciudad contemporánea y, por tanto, en tema adecuado para una ejercitación académica capaz de dotar de una base reflexiva a la práctica profesional, condición sin la cual la tarea universitaria sirve de bien poco.

1 Este libro presenta una reflexión académica y profesional en el Campus de la Diagonal con un amplio conjunto de ideas urbanísticas que permiten establecer un nuevo escenario universitario y mejorar la relación con la ciudad.

Durante los años sesenta y setenta del siglo pasado se realizaron diversos proyectos de edificios y recintos universitarios de gran interés (de Carlo, Candilis, Sert). También se publicaron notables estudios sobre la relación entre la ciudad y la universidad.

Sobre la base de una reconsideración de la relación histórica entre la ciudad, la universidad y el espacio público, y en particular de la evolución de las universidades y los campus en Barcelona, este libro pretende recuperar el rico diálogo entre espacios de formación y la ciudad. Y lo hace con tres entradas distintas y complementarias. La reflexión sobre la responsabilidad que tiene la universidad de contribuir a construir ciudad, la que aportan los proyectos que tendrán que hacerlo posible en el denominado Campus de la Diagonal, y el ensayo, tanto más interesante cuanto menos contenido, de los alumnos de un último curso de Urbanismo sobre la extensión de este campus hasta el final de la avenida Diagonal. 
Esta reflexión nos sirve sin duda para apuntalar un posible discurso entre campus y ciudad, en el que encontraríamos diversas y dispares posturas. Jaime Lerner $^{2}$ en la publicación "Acupuntura urbana", editada por IAAC 2005 en Barcelona, incorpora el siguiente texto:

"Hacer que un estudiante salga a la calle también es fundamental. En muchos lugares, los estudiantes son expulsados de la ciudad y metidos dentro de unas estructuras que convencionalmente se llaman campus universitarios. A veces el espacio está tan vacio que es un verdadero desertus universitario. Los estudiantes necesitan convivir más con la ciudad para tener una visión más generosa de la sociedad. Si no, recibirán sólo unas gotas de información sobre una sociedad con la que apenas conviven.

¿Se imaginan una Sorbonne fuera de París, o una Columbia fuera de New York, o una Berkeley separada de la ciudad? ¿O la Universidad de Heidelberg, la Facultad de Derecho de Sao Paulo, lejos del núcleo urbano?

Incluso con las estructuras centralizadas de algunos campus, es posible llevar sectores al centro de la ciudad, principalmente los relacionados con los seminarios, las actividades culturales, etc. O, si no, llevar la ciudad a los campus".

Y con estas palabras se posiciona en el debate sobre si la universidad se ha de definir en un recinto alejado de la ciudad o si se ha de integrar formando parte de ella, como en los más antiguos establecimientos del saber o como propuso Thomas Jefferson en Charlottesville para la Universidad de Virginia, arquetipo del espacio universitario moderno, con su propio campus y espacios de relación universitaria en una posición relativamente próxima al centro.

Según Carlos Carreras, catedrático de Geografía Humana de la Universidad de Barcelona, desde el punto de vista de la localización de las universidades en relación al espacio urbano, se puede hablar de dos modelos claramente contrapuestos. Uno, el primero históricamente, es el modelo europeo de la localización nítidamente urbana; el otro es el modelo anglosajón de la localización periurbana o casi rural.

La universidad medieval estaba relacionada con la Iglesia y los primeros centros de enseñanza superior aparecieron vinculados a conventos, monasterios, iglesias y catedrales. Siendo estas instituciones mayoritariamente urbanas, lógicamente, también lo fueron las universidades.

La sede central de la Universidad de Barcelona (UB) varía con el tiempo su localización: en la Rambla de los Estudios primero (coincidiendo con el tramo septentrional de la cosmopolita Rambla de Barcelona), en el Ensanche después 3 (siguiendo el proyecto del arquitecto Elias Rogent frente a la actual plaza de la Universidad) y expandiéndose posteriormente por diferentes ámbitos de la ciudad en la medida de su crecimiento.

2 Jaime Lerner, arquitecto y urbanista, ha sido alcalde de Curitiba durante tres mandatos y Gobernador del Estado de Paraná durante dos periodos de gestión. Además, ha sido presidente de la Unión Internacional de Arquitectos y actualmente desarrolla proyectos estratégicos en distintas ciudades, después de una experiencia ejemplar en Curitiba.

3 De hecho, entre el emplazamiento de la Rambla y el edificio de Elias Rogent suceden muchas cosas. En 1717, el rey Felipe $V$ suprimió oficialmente la enseñanza superior en Barcelona, Girona y Lleida como uno de los actos de represión contra Cataluña después de la Guerra de Sucesión y los emplazó en la ciudad de Cervera que había sido fiel a su régimen. Esta situación duró hasta el Trienio Liberal surgido de las Cortes de Cádiz reutilizándose el antiguo convento del Carme. El mismo Elias Rogent había diseñado el 1860 una nueva sede universitaria en los mismos terrenos del antiguo convento hasta que redactó el proyecto del edificio erigido en la Gran Vía una vez aprobado el Plan de Ensanche Cerdà ocupando un lugar estratégico de transición entre el núcleo antiguo y el nuevo ensanche. 


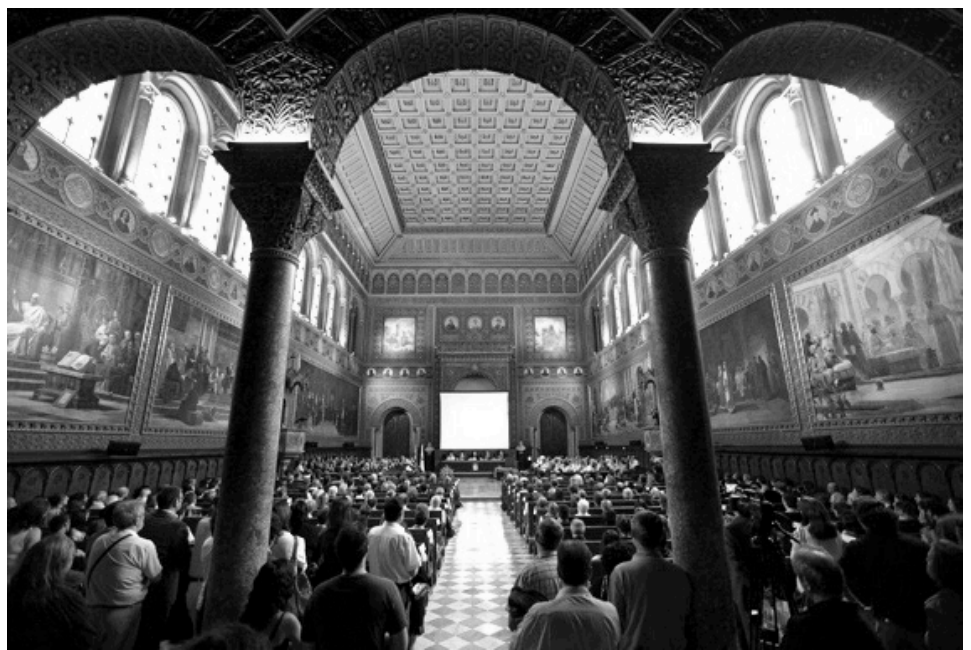

Fig. 2a Edificio histórico de la Universidad de Barcelona proyectado por Elias Rogent. Paraninfo.

$\mathrm{Y}$ en estas posiciones más urbanas encontraríamos innumerables casos. La misma Universidad de Columbia en New York ocupa manzanas enteras, o parte de ellas, y se funde en el tejido urbano de Manhattan como pasa con la Universidad de Liverpool y en tantas otras comunidades del saber.

En Barcelona, la Universidad Pompeu Fabra, también se inserta inicialmente en el tejido de la ciudad compacta, pretendiendo que su campus sea la propia ciudad. Algo parecido pasa en la antigua Universidad de Lovaina, donde las facultades se mezclan en la trama urbana sin formar grandes conjuntos docentes específicos. En Madrid, en cambio, sólo un 4,5\% de las universidades están plenamente integradas al centro de la ciudad ${ }^{4}$, mientras que la mayoría ocupan la periferia urbana del sistema metropolitano.

Por otra parte, la capacidad de acoger a la sociedad del conocimiento a que está predispuesta una ciudad, es a priori obvia, siempre que no haya fuertes obstáculos que lo impidan. En el caso de la Universidad de Bolonia, la más antigua de Europa, la aceptación fue tal que para acoger al alud de estudiantes proveniente de todas partes, y a falta de residencias, se llegó a conceder el derecho de voladizo sobre el espacio público a las edificaciones de aquellas familias que acogían a un estudiante en su casa.

Un interesante campo de investigación podría versar en definir los factores que han condicionado la localización de los campos universitarios. Encontraríamos un amplio conjunto de tipologías y de relaciones distintas entre la universidad y la ciudad desde las más solipsistas a las más integradas al tejido urbano. Sin duda, factores como la oportunidad de la disposición de suelo a menudo han condicionado una localización fuera de la ciudad, y han

4 P.Campos Calvo-Sotelo. Campus - Madrid. Urbanismo y Arquitectura en les Unidades de la Comunidad de Madrid. Dirección General de Urbanismo y Planificación Regional de la Comunidad de Madrid, 2007. 
aparecido campus lejos de la masa crítica urbana, muchos sin un sistema de transporte público eficaz. Esta disfunción ha derivado, a menudo, en un fracaso, obligando muchas veces y con posterioridad a la Administración pública a realizar importantes esfuerzos financieros para corregir decisiones proyectuales tomadas precipitadamente.

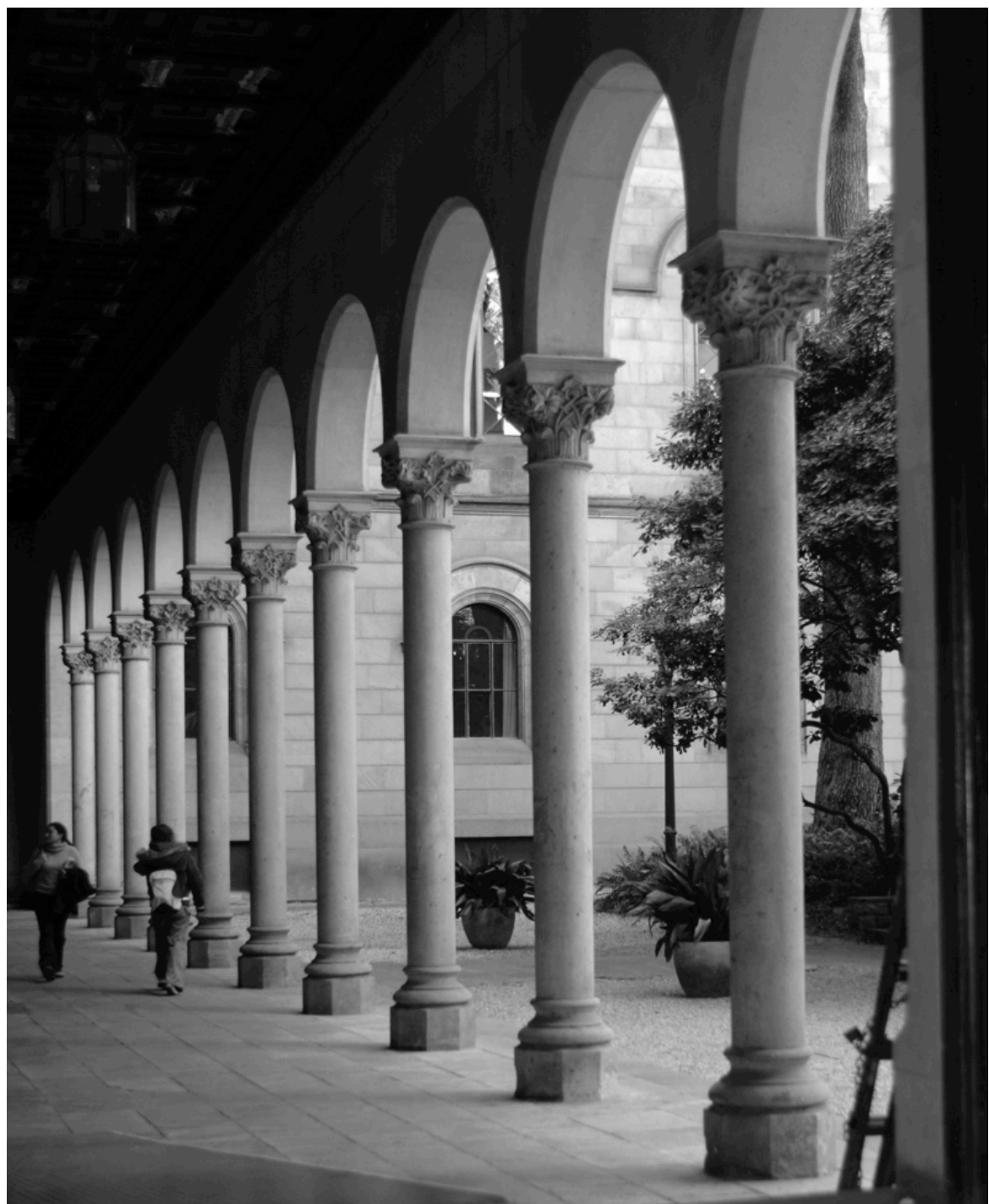

Fig. 3b Edificio histórico de la Universidad de Barcelona proyectado por Elias Rogent. Patio central. 
Pero también se han construido universidades lejos de la ciudad por conveniencia política, con la finalidad de tener a los estudiantes alejados y así evitar conflictos y altercados dentro de la misma. Este es el caso del Instituto Superior Politécnico de la Habana, proyectado por el régimen de Fulgencio Batista, antes de la Revolución. Situado a unos veinte kilómetros del centro de la ciudad, ocupa una antigua plantación de caña de azúcar simulando que el objetivo principal de esta localización era aproximar la universidad a la industria del campo.

La Universidad Autónoma de Barcelona, nacida de los conflictos universitarios en pleno régimen franquista, se emplazó al norte de las montañas de Collserola en un campus suburbano y suficientemente separado de la ciudad compacta. En este caso se tuvo que dotar de un enlace ferroviario eficaz, prolongando la línea de los Ferrocarriles Catalanes para conectar la universidad con el centro de la ciudad de Barcelona.

El propio Campus de la Diagonal que presentaré con más atención en este mismo artículo, al principio y también en pleno régimen del General Franco, fue ubicado lejos de la ciudad, dividido por la gran avenida Diagonal, que era ideal para el acceso de la policía a un campus inicialmente "mal" planificado.

Actualmente este campus ya se encuentra en continuidad con el tejido urbano consolidado de Barcelona, con excelentes comunicaciones de transporte público y con un proyecto que pretende reforzar, aún más, su integración con la ciudad.

Otro motivo de reflexión es verificar hasta que punto una universidad urbana se integra a la dinámica de su ciudad. Un buen ejemplo es la paradigmática relación entre universidad y ciudad que imprimió Josep Lluís Sert en su intervención urbanística de Harvard en los años cincuenta y sesenta del siglo pasado. Sert propuso un plan integral para un campus que se iba mezclando sin control y a gran velocidad con el tejido urbano de Cambridge. De hecho, su intervención fue estratégica con pequeñas actuaciones, pero vitales para garantizar la continuidad de los itinerarios de peatones, organizando la ordenación de los nuevos edificios, a veces con el recorrido peatonal, creador de ciudad, por el interior de la misma edificación, como pasa en el Holyoke Center, que Sert proyectó y fue clave para la articulación del campus y la ciudad. También sugirió el paso inferior por la Cambridge Avenue con el objetivo de unir el recorrido peatonal y sin coches entre el antiguo Yard y el Campus Norte.

Ahora bien, nos queda un importante campo de exploración relacionado con la idea del campus, que va más allá de su propia definición y que en su concepción más moderna comporta implícitamente una idea de ciudad. El campus como estructura "pavillonaire", que hace interpretar el papel protagonista a los edificios, tensando el espacio público como pasa, aunque con otro programa, en la mágica Piazza o Campo dei Miracoli, situada en el corazón de la ciudad de Pisa, donde el espacio no se presenta como un plano horizontal libre en sí mismo, la mitad pavimentado y la otra mitad cubierto de verde, sino que el interés radica en la forma y en la posición estratégica de las cuatro grandes edificaciones: el Duomo, la torre inclinada, el Baptisterio y el Campo 
Santo Monumentale, con una carga añadida de simbolismo. Allí el espacio está definido como un elemento, se predispone y se establece como proyecto de ciudad.

Pero el poder que potencialmente tiene la arquitectura moderna, de generar un lugar urbano, no lo tienen tan claro Collin Rowe y Fred Koetter ${ }^{5}$ que nos dan a entender como se diferencian los proyectos del centro de Saint Dié o la Unité d'Habitation de Marsella de Le Corbusier del fragmento de una ciudad de la Toscana, y manifiestan su preferencia por esta última (cargada de complejidad, identidad e historia), poniendo en crisis la ciudad moderna y aduciendo que la ciudad tradicional se niega a ser establecida y que no hay referencias ni históricas ni ideales.

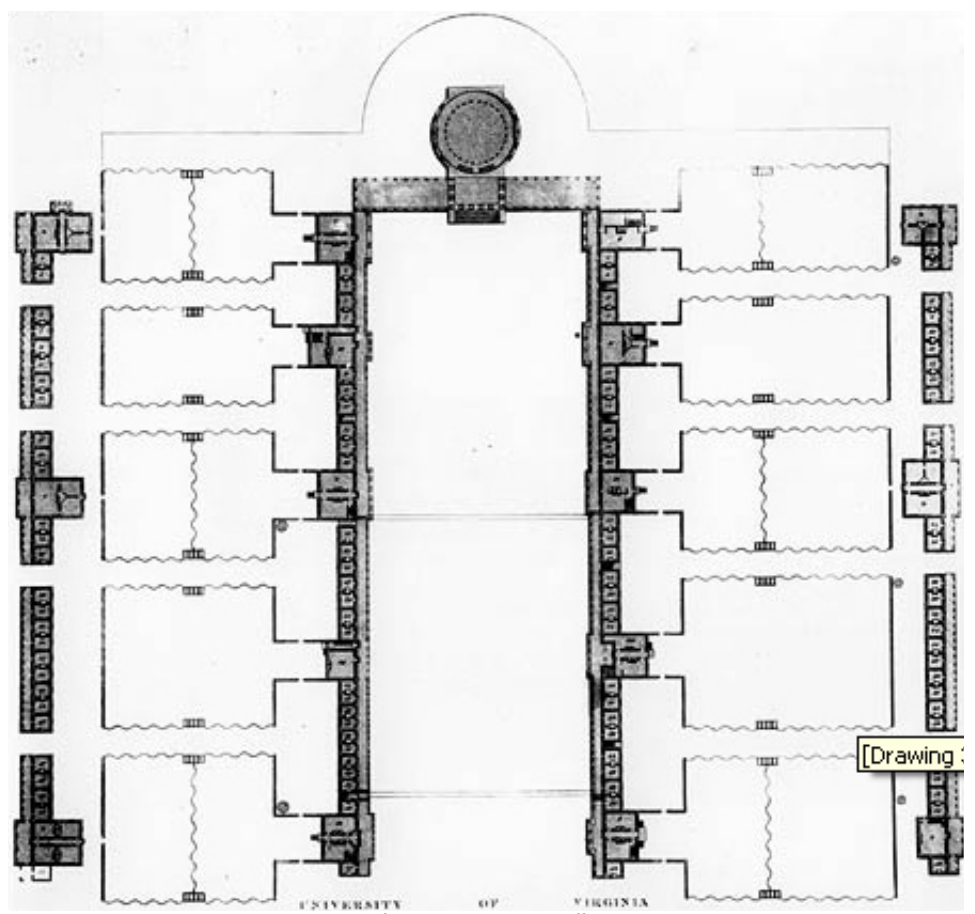

Fig. 4 Esquema de la Universidad de Virgínia, fundada por Thomas Jefferson

No estoy tan seguro de ello. Cada vez estoy más convencido de la carga de fuerza y sentido de hacer ciudad que puede imprimir la arquitectura moderna cuando en si misma existe el compromiso de proyecto urbano como pasa en el Holyoke Center de Sert. Me inclino a vindicar estas formas de relacionarse que en el mundo contemporáneo pueden adquirir los edificios como protagonistas y definidores del espacio urbano, y que donde radica la arquitectura de la 
ciudad, es en la buena relación arquitectónica entre sus espacios y edificios, sin la cual ningún objeto solo puede pretender hacer ciudad. ${ }^{6}$

En un escenario distinto, Carlos Raúl Villanueva diseñó la Ciudad Universitaria de Caracas, declarada Patrimonio Cultural de la Humanidad por la UNESCO el año 2000. Villanueva tuvo muy en cuenta la escala humana y concibió el campus como una ciudad jardín con un importante componente verde, creando recorridos o sutiles movimientos peatonales que establecen una sugestiva fruición producida por la arquitectura de los edificios que dialogan entre sí y con el paisaje urbano del campus.

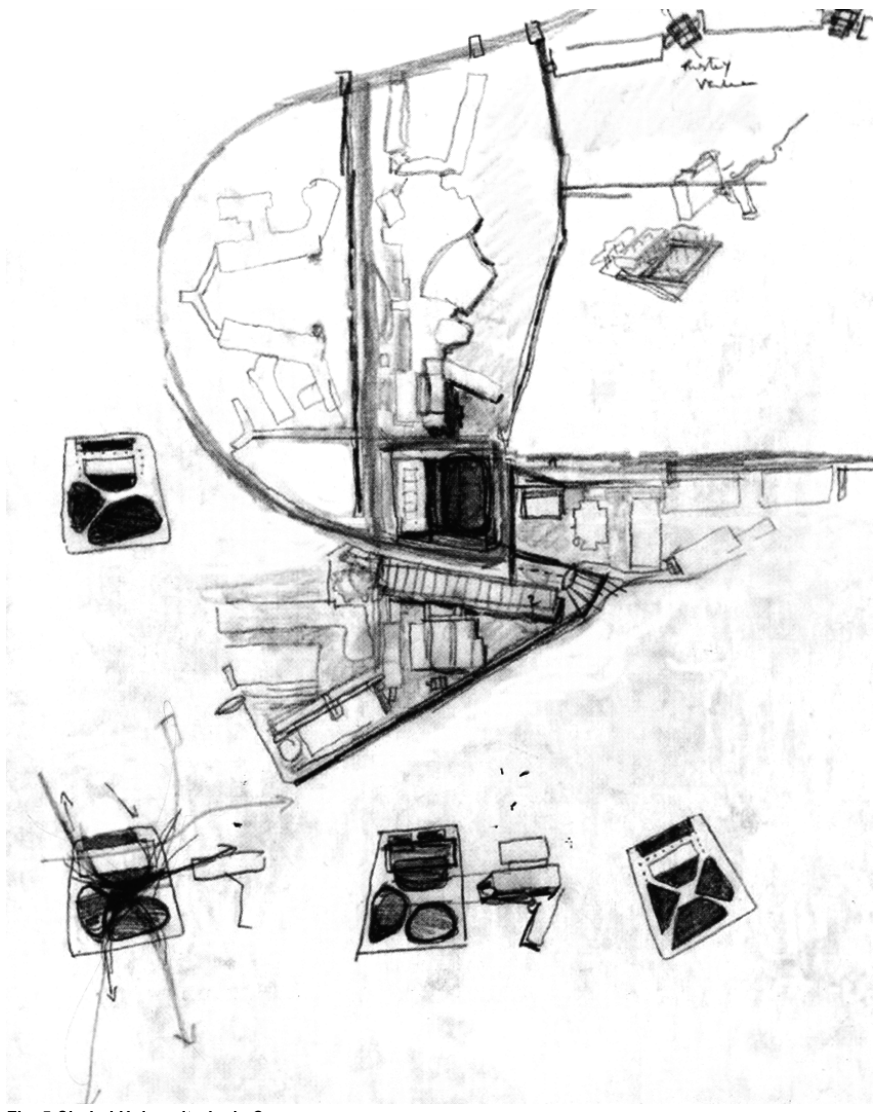

Fig. 5 Ciudad Universitaria de Caracas.

6 Manuel de Solà-Morales argumentaba en su discurso crítico del urbanismo funcional de Le Corbusier que había otra tradición en el movimiento moderno, en la arquitectura, que no pasa por la distinción tan radical entre los principios que se aplican en la ordenación de las ciudades y los que se aplican en proyectación urbanística. Una tradición que intenta moverse en la proyectación de temas complejos en los cuales la discusión de la ciudad, de la edificación, del trazado de las calles, de la parcelación de los solares, de la organización de movimientos e itinerarios e incluso la discusión relativa a la intención social de su contenido están mezclados. Aquí surge la tradición moderna del proyecto urbano, con unos tópicos comunes, entre ellos: el carácter complejo e interdependiente de su contenido, superación del monofuncionalismo (parque, vía, tipología, etc.), mezcla de usos y carga voluntaria de hacer arquitectura de ciudad, independiente de la arquitectura de los edificios. 
También cabe constatar que independientemente del régimen de propiedad, a fin de vitalizar un campus que se encuentra alejado del centro o del tejido compacto de una ciudad una buena opción proyectual puede ser la implantación de usos complementarios a los universitarios. ${ }^{7}$ Este criterio se incorporó en Barcelona tanto en el Campus Norte de la Diagonal como en el Plan de Mejora Urbana del Campus Sur, planteándolo como recurso urbano, más allá de su función docente e incorporando un componente social y ciudadano, con el objetivo de ayudar a cohesionar las partes, asegurar la continuidad de la vida urbana más allá del tiempo de docencia y, a la postre, evitar la desertización urbana.

Una corrección similar y a pequeña escala la propició Rem Koolhaas en el Illinois Institute of Technology (IIT Campus) proyectado el año 1939 por Mies van der Rohe, con la incursión de un "campus center", un edificio de servicios con sala de conferencias, comercios, cafetería, supermercado y otros usos complementarios al lado de la estación de transporte ligero que conecta con el centro de la ciudad de Chicago y su red general de transporte público.

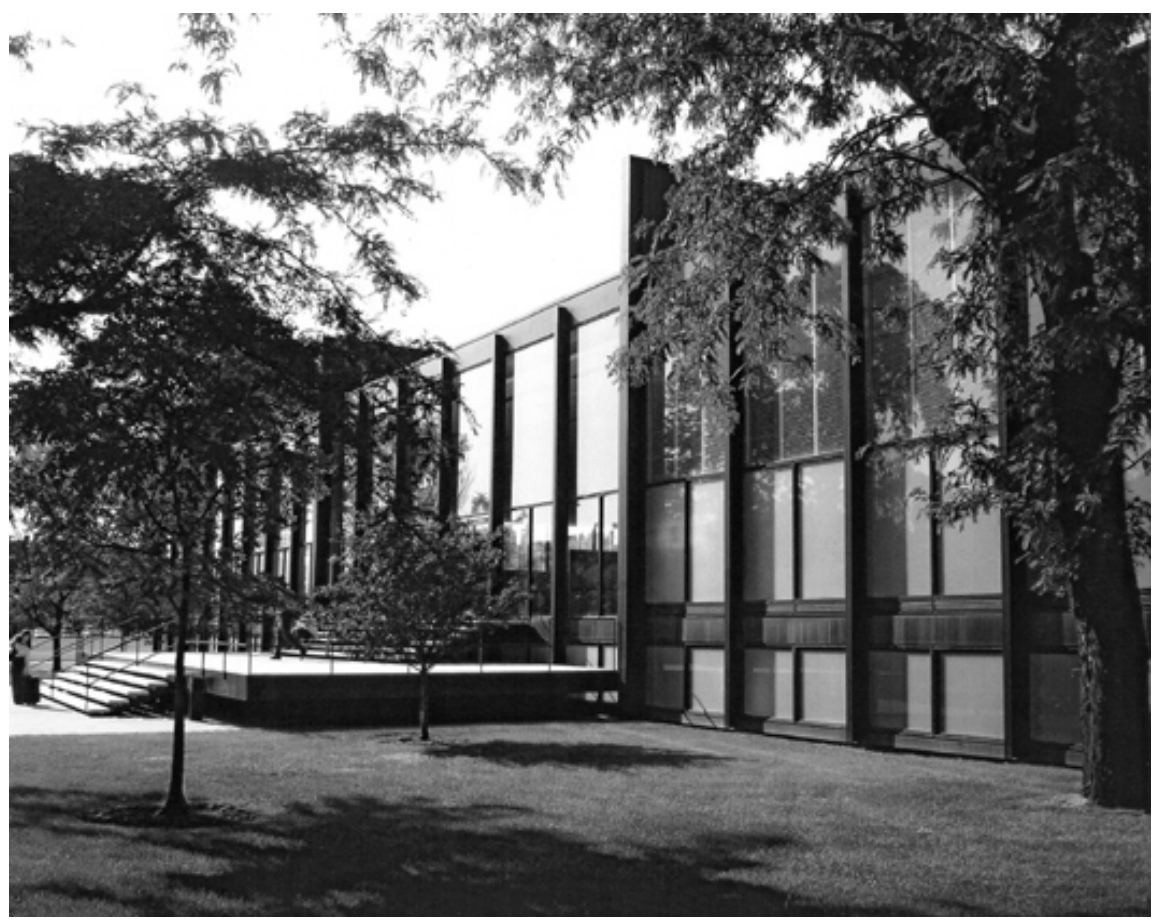

Fig. 6 IIT's College of Architecture proyectado por Mies van der Rohe

7 La concepción de los campus como ámbitos territoriales de uso exhaustivo docente cobra importancia a partir del planeamiento urbanístico derivado de los postulados de la Carta de Atenas y la potenciación del zoning. La universidad de Río de Janeiro proyectada por Le Corbusier, seria un ejemplo de campus de esta generación. Pero incluso después del congreso de Dubrovnik de 1956 en el que el TEAM X cuestiona parte de los postulados del Congreso del CIAM de 1933, entre ellos el del zoning, los campus universitarios se resisten a ser proyectados de forma fragmentada. Los paradigmáticos proyectos de S. Woods en Berlín y V. Gregotti en Cosenza y Firenze formarían parte de este otro escenario. 


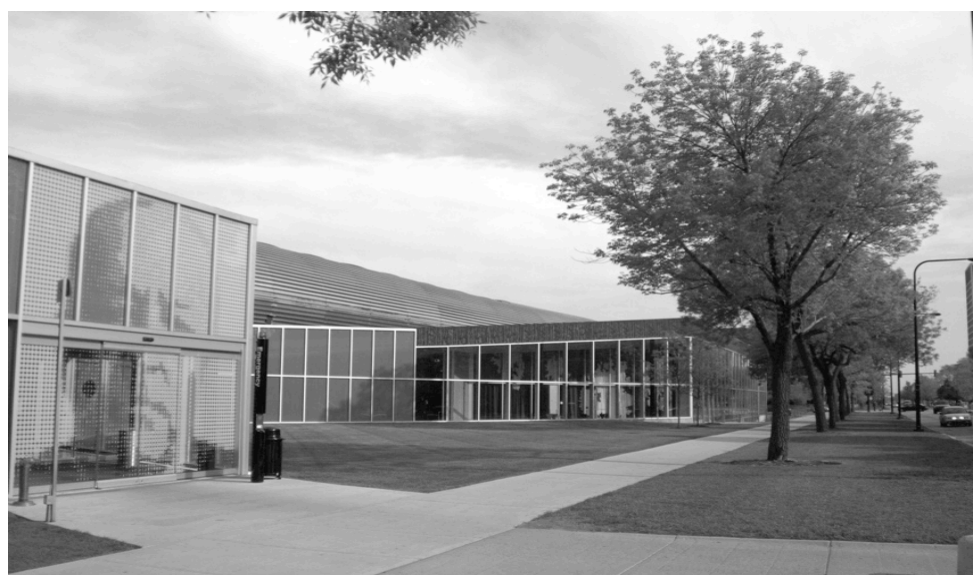

Fig. 7 Campus Center según proyecto de Rem Koolhaas

En cualquier caso, según Jeff Lackney, conviene fomentar el compromiso de diseñar recintos universitarios que principalmente tomen en consideración la calidad de vida y la experiencia social de los alumnos que habitan en estas instituciones de enseñanza superior, y el urbanismo y la arquitectura constituyen elementos fundamentales en el esfuerzo de crear las comunidades de aprendizaje más vibrantes.

\section{A PROPÓSITO DEL BARCELONA KNOWLEDGE CAMPUS BKC}

En 2009 los Ministerios de Educación y Ciencia e Innovación en España abrieron la convocatoria de Campus de Excelencia Internacional. Tras una primera selección de 18 finalistas entre más de un centenar de universidades que formularon su propuesta, obtuvieron la prestigiosa distinción once candidaturas, entre ellas la del Barcelona Knowledge Campus (BKC).

Una Comisión Internacional de expertos integrada por el arquitecto Dominique Perrault, el científico Ignacio Cirac, el exrector de la Universidad de Viena y dirigente de la asociación de universidades europeas Georg Winckler, distinguió tres grupos entre las once candidaturas en función del potencial y la proyección internacional de las propuestas. La bipolaridad Madrid-Barcelona era llamada a impulsar la modernización del sistema universitario español, y con esta hipótesis la Comisión Internacional premió los proyectos de Madrid Universidad Complutense y Politécnica de Madrid, Universidad Autónoma (UAM) y la Universidad Carlos III, así como los proyectos de la Universidad de Barcelona y la Universidad Politécnica de Cataluña que se presentaban conjuntamente bajo el nombre de "Barcelona Knowledge Campus" y de la Universidad Autónoma de Barcelona (UAB), por su potencial de competencia internacional. Un par de años antes, previa a su presentación, había redactado, junto con el profesor del Departamento de Proyectos Arquitectónicos de la Escuela Técnica Superior de Arquitectura de Barcelona, Luís Alegre Heitzmann, el Plan de Mejora Urbana del Campus Sur de la Diagonal. 


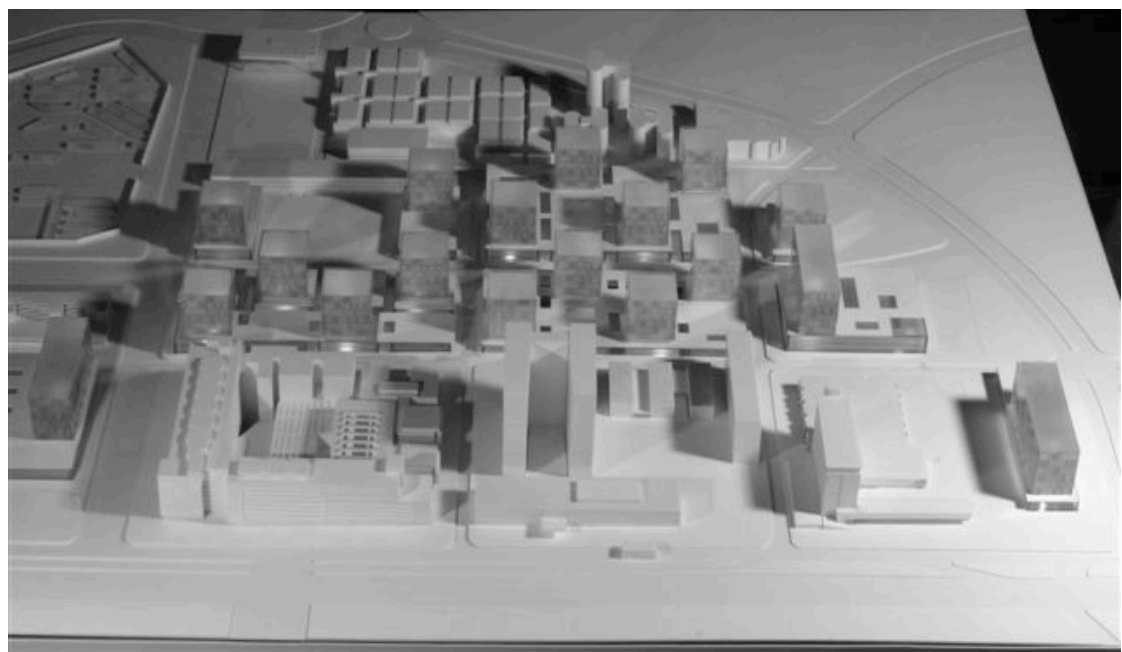

Fig. 7 Imagen de la maqueta

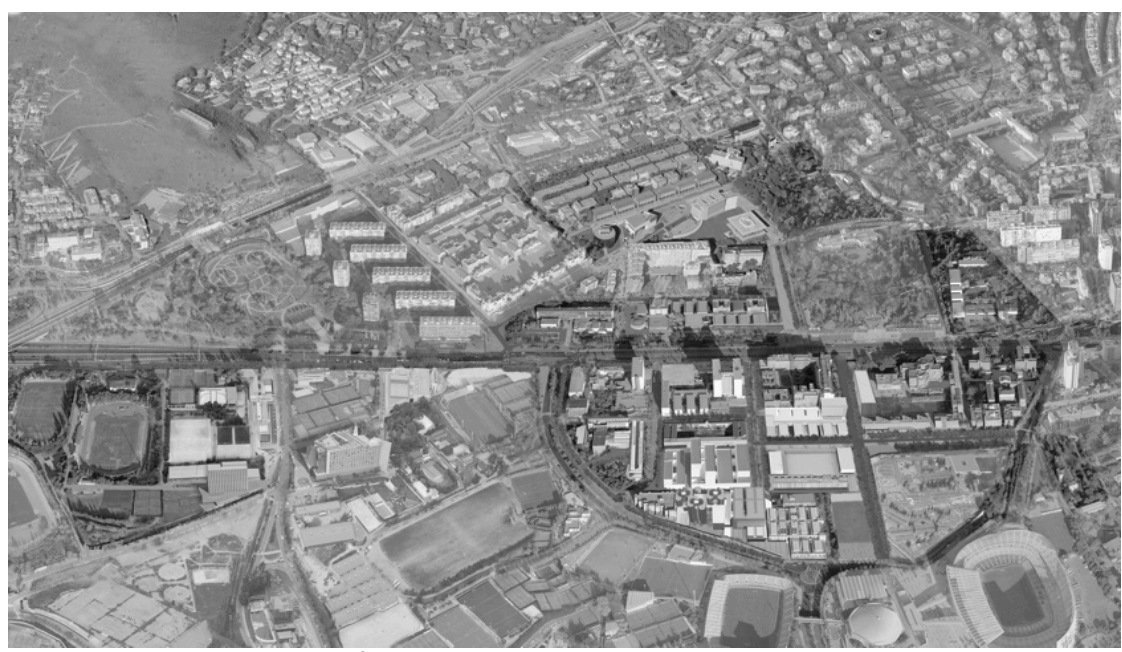

Fig. 8 Imagen aérea de la propuesta del BKC

Además, en la última asignatura troncal de Urbanismo de la ETSAB, habíamos escogido este campus para los ejercicios de taller en dos cursos seguidos. Trabajar en un espacio tan cercano a las aulas, donde además se realizaba una reflexión urbanística y proyectual a nivel profesional, resultó muy satisfactorio y se tradujo en una gran implicación de los alumnos y en un notable nivel de sus ejercicios.

La presentación de la candidatura del Barcelona Knowledge Campus para la cual tuve la ocasión de elaborar el contenido urbanístico y la ordenación de los edificios, fue también una experiencia muy interesante, ya que se producía 
tras una experiencia previa y un trabajo de investigación que desde hacía años compartía con mis compañeros del Departamento de Urbanismo y Ordenación del Territorio. También sirvió en gran medida el documento de reflexión sobre los criterios de urbanización del Campus Sur que habíamos elaborado recientemente. Estos criterios apostaban por la peatonalización y la pacificación del tráfico, como ya se había producido en el modelo establecido en el Campus Norte de la UPC.

Planteábamos la extensión a otra escala de la malla regular de la ordenación de las calles del Campus. Creíamos conveniente transportarla a la composición de los edificios y a su ordenación dentro de las parcelas como ya se había realizado anteriormente en otras actuaciones, entre ellas la de la Escuela Técnica Superior de Ingeniería Industrial de Barcelona.

Una vez conocidos los programas funcionales, decidimos concentrar los aularios de las nuevas facultades en unos volúmenes-zócalo de planta baja y una o dos plantas piso como máximo, por razones de albergar la masa crítica del alumnado lo más cercana posible de la cota de planta baja y, en todo caso, destinar unos volúmenes emergentes a despachos, seminarios, investigación y a dependencias departamentales. Gran parte de la cubierta de los volúmenes zócalo podría ser vegetal y convertirse en un espacio colectivo de las mismas facultades.

Nuestro plan también regulaba la disposición de los edificios emergentes de los volúmenes-zócalo mediante un mecanismo reglado para asegurar el asoleamiento del conjunto y un criterio unitario en los proyectos.

Implícitamente se trabajaba a doble escala, la humana o del peatón establecida por los volúmenes-zócalo y la de la ciudad en la que los edificios emergentes tomaban su protagonismo, erigiéndose como verdaderos iconos urbanos. Todo ello permitió establecer un nuevo modelo de Campus sostenible, funcionalmente integrado y ambientalmente eficiente, el Barcelona Knowledge Campus BKC, un Campus de Excelencia Internacional.

Compuesto por la Universidad de Barcelona (UB) y la Universidad Politécnica de Cataluña (UPC), constituye un "cluster" de formación de primer orden y referencia en el sur de Europa y basa su estrategia en el liderazgo de un cambio de modelo económico de su entorno. Es un campus integrado en el continuo del tejido de la ciudad de Barcelona y cuenta con planes y proyectos encaminados a fortalecer esta condición urbana.

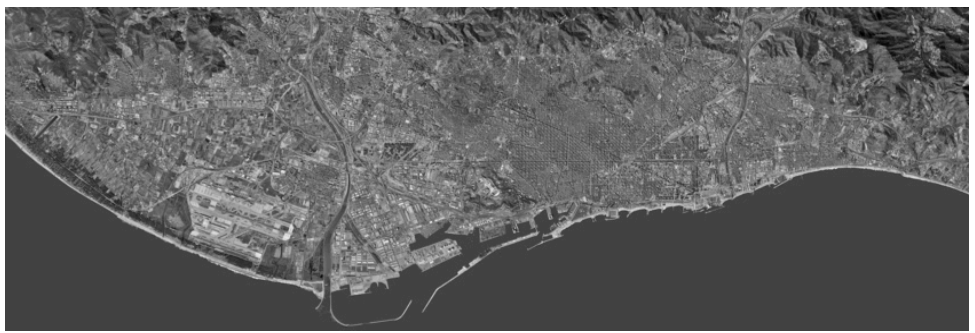

Fig. 9 La ciudad de Barcelona y el BKC 
La innovación de sus propuestas y programas resulta adecuada en el sistema universitario español, en la medida que cuenta con diversidad tecnológica, propuestas académicas novedosas y el reconocimiento como Campus de Excelencia Internacional potenciará al alza sus activos de atracción en la sociedad del saber.

Por otra parte, la alta concentración de conocimiento de este campus urbano, más de 50.000 alumnos repartidos en 16 centros docentes y 90 departamentos, es un activo relevante y positivo de una gran capital como es Barcelona, que cuenta con una extensa área metropolitana y un eficaz sistema de comunicaciones y transporte público.

Uno de los factores clave del Barcelona Knowledge Campus radica en su posición al pie de la avenida Diagonal ${ }^{8}$, que pasa de ser una vía de $\mathrm{NO}$ integración de la "Zona Universitaria" (denominación inicial) al elemento de cohesión principal. La avenida Diagonal, en su tramo poniente, flanquea de forma continua el Campus en un par de kilómetros de longitud, condición que hace que los edificios y espacios universitarios confrontantes a esta vía caractericen una secuencia de gran significación urbana, coincidiendo con la puerta de la ciudad consolidada desde poniente.

La imagen de la ciudad desde este episodio urbano es quizás la más relevante de Barcelona, con una perspectiva amplia hacia ella con el mar al fondo y desde la que se visualizan los principales hitos urbanos que emergen del paradigmático Ensanche Cerdà, abrigado a poniente por Montjuïc, su montaña más urbana. Esta imagen cobra significación en el detalle por la presencia de edificios del propio Campus, algunos de ellos con importantes premios de Arquitectura como es el caso de la Facultad de Derecho y la ampliación de la Escuela Técnica Superior de Arquitectura, sin olvidar la Escuela de Estudios Mercantiles ni la mencionada Escuela Técnica Superior de Ingeniería.

Los jardines diseñados por Nicolau $\mathrm{M}^{\mathrm{a}}$ Rubió y Tudurí para el Palacio Real que acoge, desde hace poco, la sede de la capitalidad del Mediterráneo y el recientemente premiado parque de Cervantes, este último conectado con el gran parque de la sierra de Collserola, son importantes pulmones que se encuentran en continuidad e integrados en el mismo ámbito estructural del Campus. Además, con la propuesta de aumentar el ancho del espacio de estancia y paseo del lado norte de la Diagonal se favorecerá la relación entre las facultades y la unión entre los citados parques, constituyendo con el resto de espacios libres existentes y los que se propone obtener con la transformación de la sección viaria, un singular sistema de espacios libres dentro de la ciudad.

El Campus Norte, así conocido por estar situado en la parte septentrional de la avenida Diagonal, con un tejido universitario de nueva generación de la UPC prácticamente acabado, y la sede del rectorado en la Torre Girona con sus espléndidos jardines se integran a la perfección al sistema de espacios libres propuesto.

8 La avenida Diagonal junto con la Gran Vía de las Cortes Catalanas y el Paseo de Gracia es una de las arterias viarias más emblemáticas de la ciudad. 


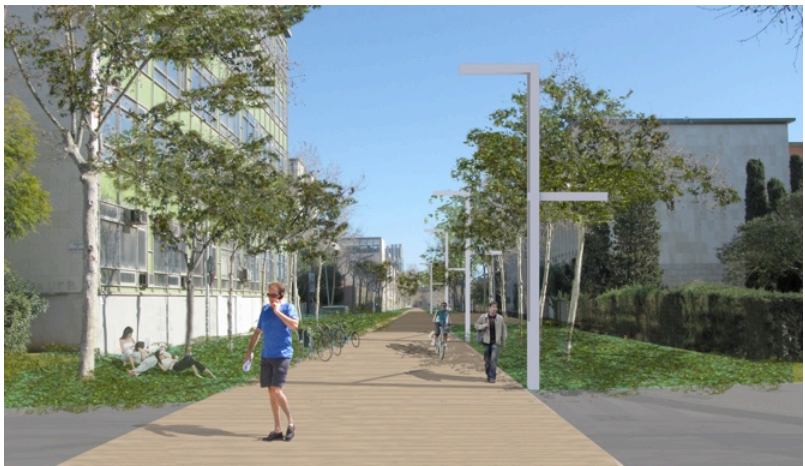

Fig. 9 Ejemplo de peatonalización en la calle Pau Gargallo

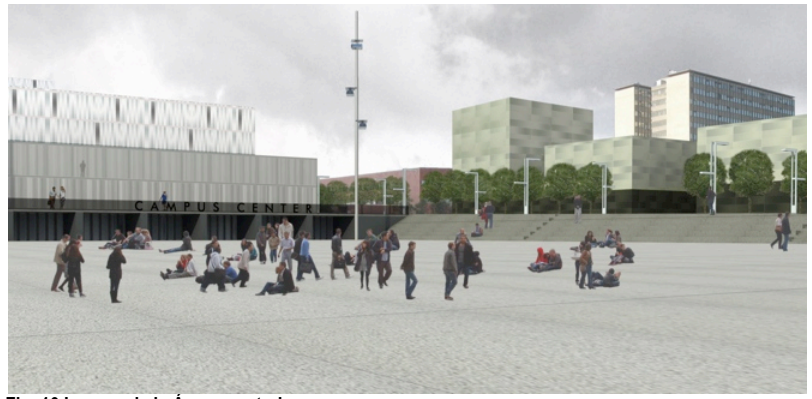

Fig. 10 Imagen de la Ágora central

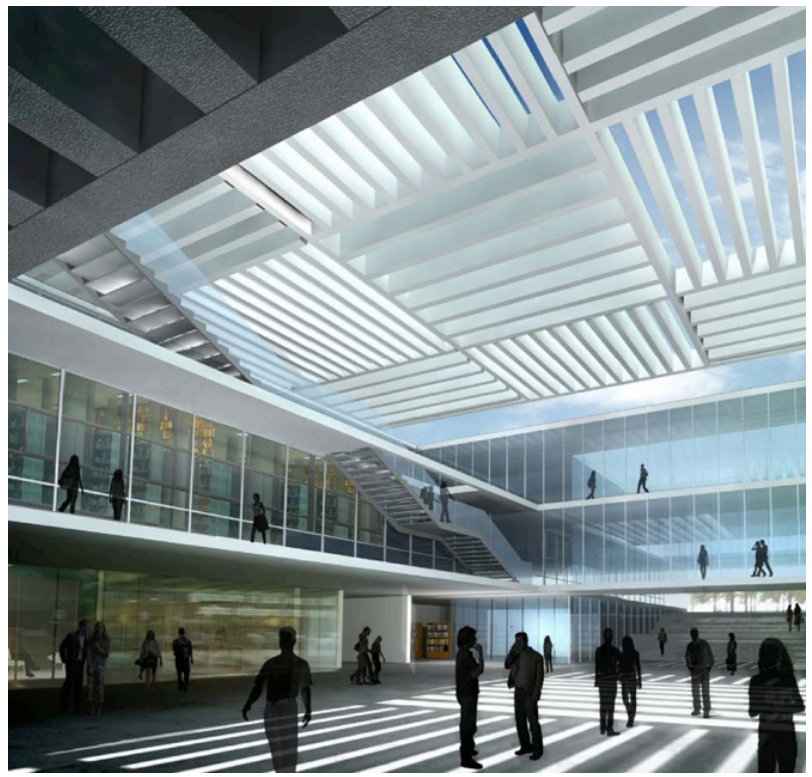

Fig. 11 Atrio de la nueva Facultad de Farmacia 


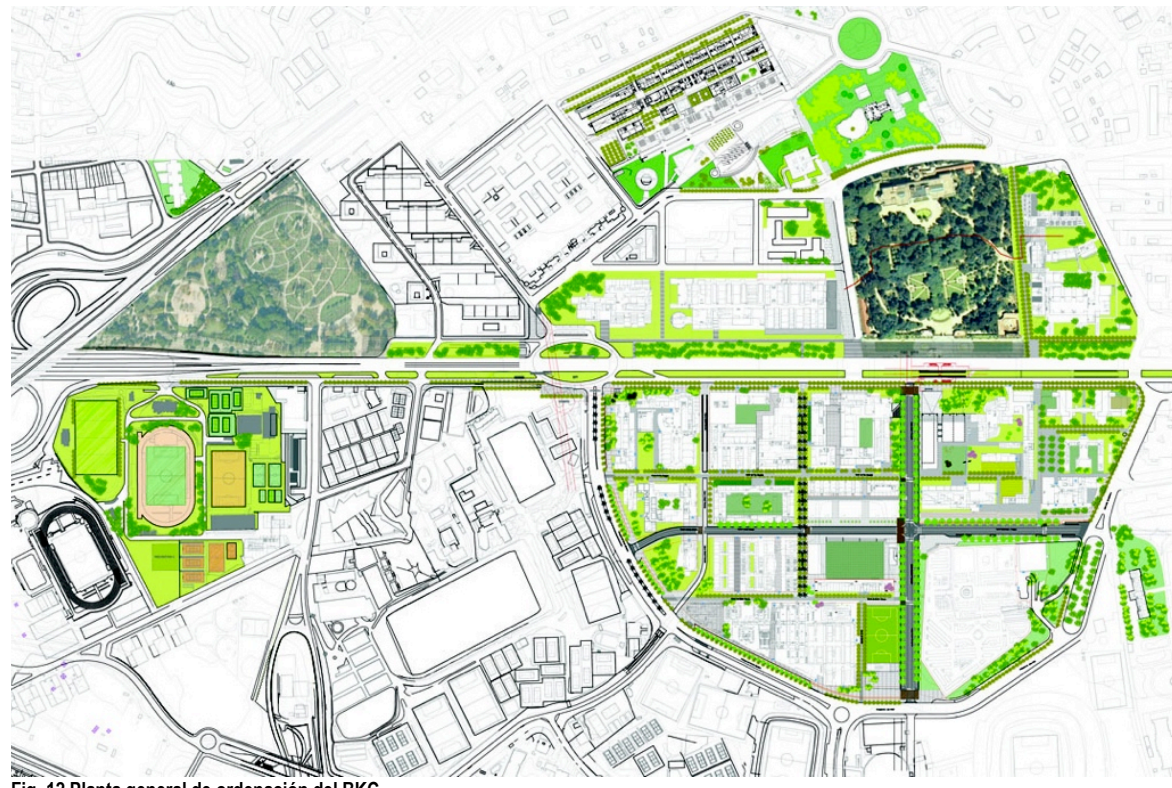

Fig. 12 Planta general de ordenación del BKC

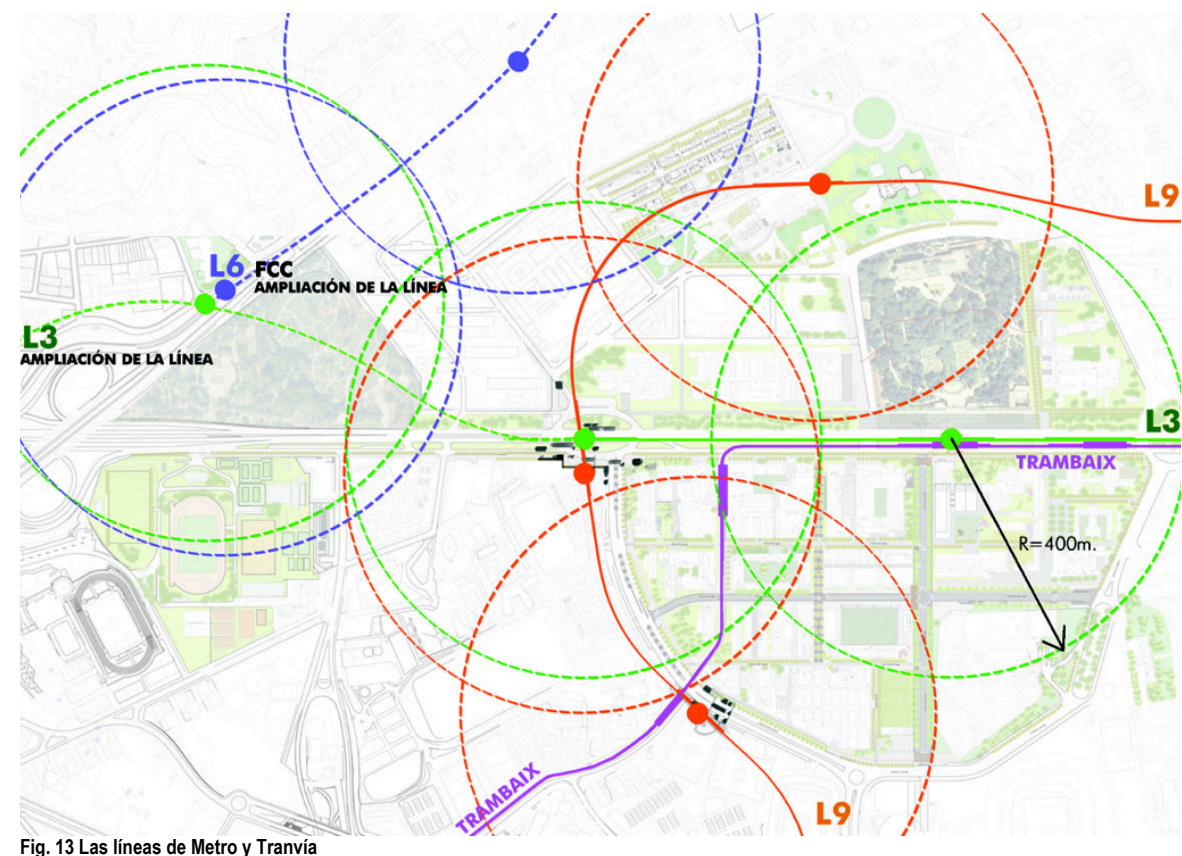




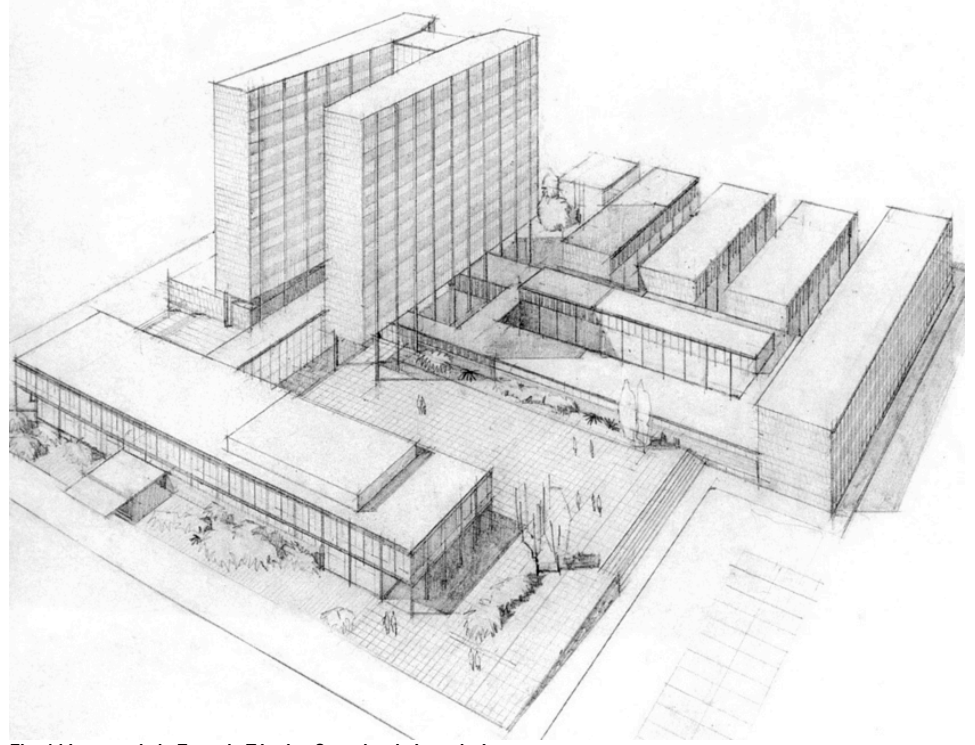

Fig. 14 Imagen de la Escuela Técnica Superior de Ingeniería

El Campus Sur, por su parte, con más antigüedad, se encuentra en constante renovación, y sigue un modelo establecido en planes aprobados y proyectos $^{9}$ que lo sitúan en el primer orden urbano y del ámbito universitario. El Recinte d'Esports, por otra, situado en el extremo más a poniente de la avenida Diagonal, frente al parque de Cervantes, también ha sido motivo de reflexión y recomposición a partir del proyecto de la nueva residencia de estudiantes que será su icono, ocupando una posición emblemática y tensando su relación hacia el Campus Sur.

Desde el punto de vista de la movilidad, podemos asegurar que está garantizado un óptimo funcionamiento del Campus y de las ampliaciones programadas. Las líneas de metro L3, L5 y L6, con las prolongaciones proyectadas, que pronto serán complementadas por la línea L9 en construcción, cuyo recorrido será el más largo de Europa, con tres paradas en el Campus de la Diagonal, le otorgan una gran accesibilidad, sinónimo de centralidad. Además, la presencia del tranvía que se inserta en el mismo Campus con cuatro paradas y una amplia red de líneas de autobuses urbanos e interurbanos con paradas en su ámbito, fortalecen aún más el modelo de movilidad sostenible que se propone.

9 A partir del Plan de Mejora Urbana redactado por los arquitectos Estanislau Roca y Luís Alegre, en el Campus Sur, la Universidad de Barcelona entre 2007 y 2008 convocó los concursos de selección de proyectos de los edificios correspondientes a la nueva Facultad de Farmacia, la ampliación de Bellas Artes y un edificio del Centro de Infraestructuras Científicas para la Investigación y la Innovación Tecnológica (CICRIT).

Fruto de estos concursos se ha encargado a los equipos ganadores los correspondientes proyectos de edificación, a saber, el proyecto de la nueva Facultad de Farmacia a los arquitectos Luís Alegre, Estanislau Roca, Lluis Lloveras, Antoni Barceló, Bárbara Balanzó y Jaume Sanmartí, la ampliació de la Facultad de Bellas Artes a Forgas Arquitectes S.L. y el proyecto del CICRIT a Espinet-Ubach, Arquitectes i Associats S.L. 


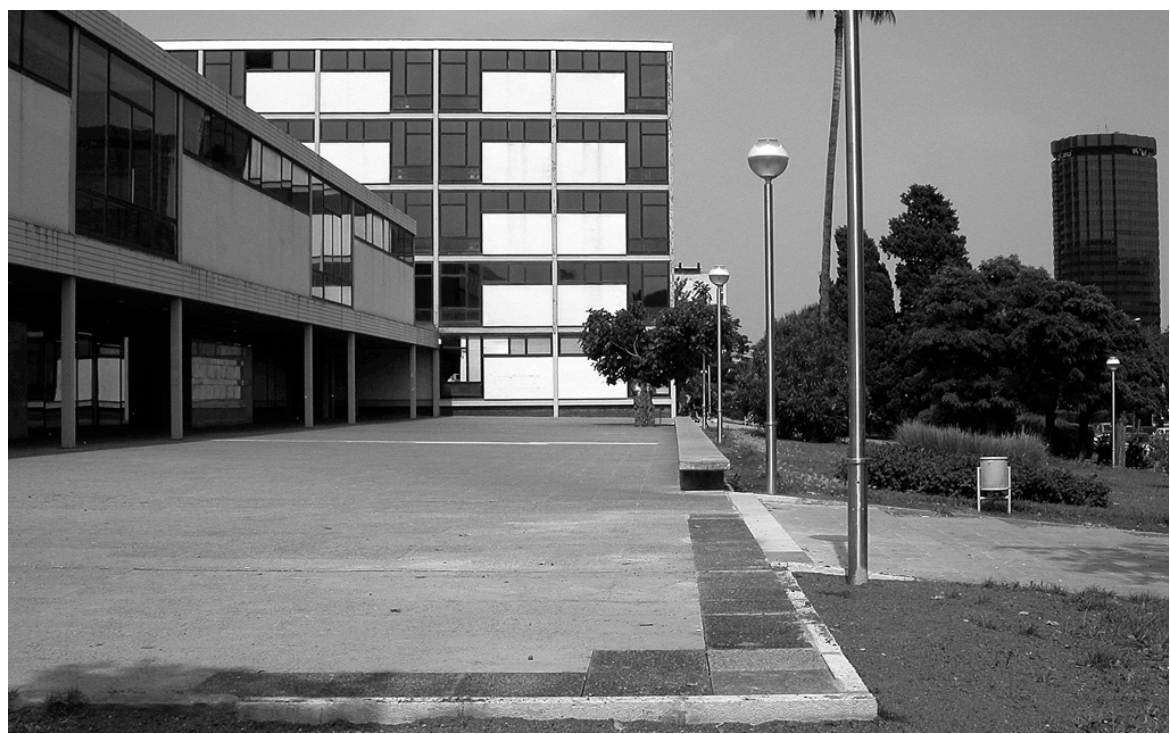

Fig. 15 Imagen de la Facultad de Derecho

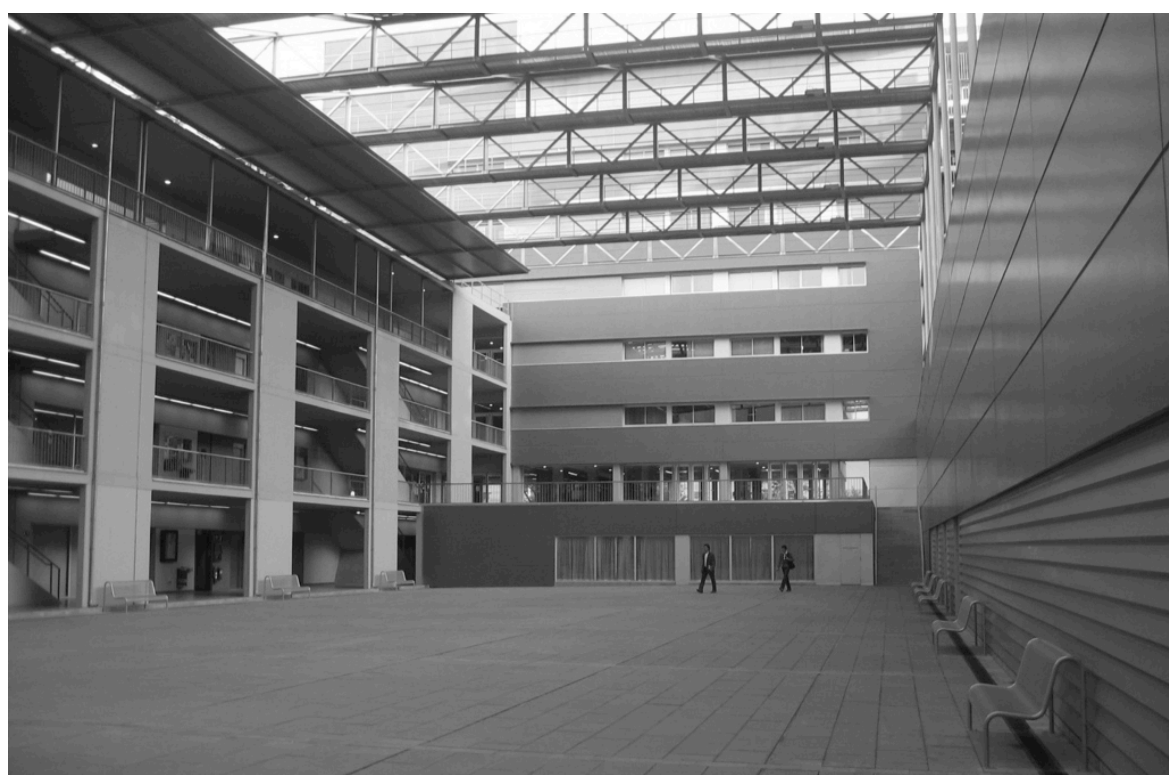

Fig. 16 Atrio solar Facultades de Física i Química 
Todo ello ha motivado un cambio en la vialidad para el Campus Sur propuesto en el Plan de Mejora Urbana aprobado y en los criterios de urbanización que apuestan por aumentar el arbolado y dar prioridad a los peatones y a las bicicletas. Se pacifica todo el recinto universitario con la transformación de la sección viaria de las calles, dejando solamente una plataforma central de unos 6 metros para los peatones, bicicletas y vehículos de servicio y el resto de la vía con un tapiz verde. La única inserción del tráfico rodado se establece a una velocidad máxima de $30 \mathrm{Km} /$ hora en dos víasbulevar (calles Martí Franquès y Menéndez Pelayo) dispuestas en forma de cruz, como si de un cardo y decumanus maximus del siglo XXI se tratara, y con ellas se construye un claro esquema estructural del Campus ${ }^{10}$.

Estas vías establecen la conexión con el tejido viario circundante para asegurar la presencia de la ciudad dentro del Campus. En las plantas bajas de los nuevos edificios se impone normativamente un importante porcentaje de usos complementarios para la comunidad universitaria, que a la vez son atractivos para el ciudadano en general y ayudan a favorecer la integración a la ciudad. Además, la presencia ciudadana se verá reforzada con la localización de un equipamiento para el barrio de les Corts frente a una gran Ágora, situada en el epicentro del Campus Sur donde se cruzan las dos vías principales referenciadas.

Los usos colectivos que se establecen en el entorno del Ágora universitaria y frente a los bulevares mencionados serán grandes activos que ayudaran a vitalizar este campus-ciudad. Además, el Ágora central o plaza cívica será el verdadero corazón del Campus Sur de la Diagonal siguiendo el modelo de interactividad de las otras plazas del Campus Norte. Aquí se apuesta por la presencia de edificios de servicios y con una posible residencia para estudiantes y profesores. De esta forma se fomentará la interrelación disciplinar y social del estudiantado de las distintas facultades y se saldará el tributo de autismo característico de muchos edificios de campus universitarios. Y la mezcla de usos permitirá evitar la desertización urbana propia de un campus de uso exclusivamente docente cuando acaba su actividad y así garantizar la continuidad de la vida urbana. Otros aspectos positivos son el cambio de perfil del profesorado con cada vez más dedicación a la investigación, el nuevo perfil de los investigadores y la actividad económica y empresarial que genera la transferencia de conocimiento con horarios que alargan la actividad en el Campus. ${ }^{11}$

El ciudadano además de poder visitar el Campus, tanto los días laborables como los festivos, podrá contar con la visita a la futura Sala de Exposiciones de la Facultad de Bellas Artes, al Museo de la nueva Facultad de Farmacia, al Patrimonio Gaudí y al Jardín Geológico proyectado frente a la Facultad de Geología, entre muchos otros atractivos que innegablemente aseguraran la presencia humana en este Campus, situado en continuidad del recinto del Camp Nou del Fútbol Club Barcelona.

10 Una de estas dos vías principales se plantea como plataforma única con una sección transversal en forma de $V$ y se recoge el agua de lluvia en el centro que junto con la del resto de calles y espacios libres del Campus está previsto pasar por unos filtros para separar metales e hidrocarburos y reutilizar esta agua para el riego del arbolado y superficies verdes del Campus.

11 Por otra parte, el Parc Científic de Barcelona, promovido por la Universidad de Barcelona, que es una infraestructura de primera magnitud al servicio de la investigación, la innovación y la transferencia de conocimiento, albergando institutos y grupos de investigación públicos y privados, spin-offs, empresas de base tecnológica, una bioincubadora..., amén de importantes servicios científico-técnicos y del nuevo Centro de Convenciones, será el gran portal de relación entre la universidad y el mundo empresarial. En el mismo sentido cabe mencionar los institutos de investigación como el Barcelona Centre Supercomputació, creado en 2005 y que cuenta con uno de los supercomputadores más potentes de Europa. 


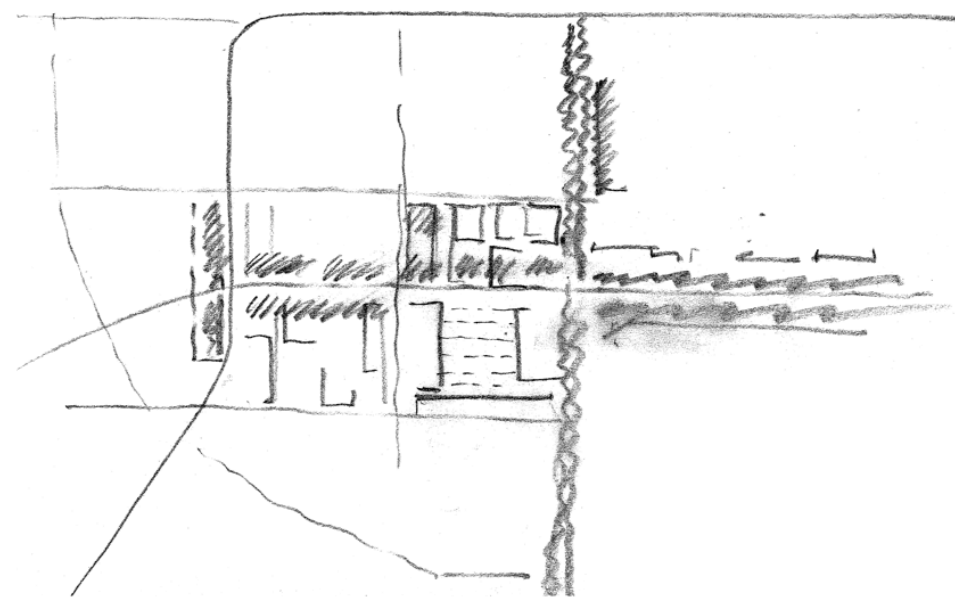

Fig. 17 Esquema conceptual del Campus Sur

También cabe poner de relieve que para asegurar la permeabilidad de las plantas bajas en sentido norte-sur, el planeamiento aprobado en el Campus Sur establece normativamente unos pasos peatonales en planta baja en los nuevos edificios docentes. El paso a través de las facultades de Física y Química de la Universidad de Barcelona con su Atrio Solar es un buen precedente de esta condición general.

En definitiva, la porosidad, tanto interna de los edificios, como la del mismo Campus, favorece la integración del Campus con la ciudad, la sociedad civil y la del conocimiento, y de las facultades con su campus, entendida también a distintas escalas, la humana, la de la ciudad y la del conocimiento.

Por todo, cabe considerar al BKC como un proyecto de unión de esfuerzos para la potenciación de la sociedad del conocimiento y la integración en el seno de su ciudad, Barcelona, tras un proceso de continua renovación y mejora urbana.

Estanislau Roca Blanch, Arquitecto Doctor en Urbanismo

Profesor del programa de Doctorado en Urbanismo

Departament d'Urbanisme i Ordenació del Territori. UPC

jane2@coac.net 


\section{Referencias bibliográficas}

BENEDITO, J. (2009). Et alt. Campus. 10 anys d'arquitectura universitària a Catalunya. Barcelona VCA Editors, $\mathrm{x}$.

BENEDITO, J. (2001). Et alt. Universitat, Arquitectura i Territori. Barcelona. Departament d'Universitats, Recerca i Societat de la Informació.

BUSQUETS, J. (1994). Barcelona, evolución urbanística de una ciudad compacta. Madrid, Mapfre.

CAMPOS CALVO - SOTELO, P. (2007). Campus - Madrid. Urbanismo y Arquitectura en las Universidades de la Comunidad de Madrid. Dirección General de Urbanismo y Planificación Regional de la Comunidad de Madrid.

CAMPOS CALVO - SOTELO, P. (2000). La Universidad en España. Historia, Urbanismo y Arquitectura. Ministerio de Fomento.

CARRERAS, C. (2001). La Universidad i la ciutat. Barcelona, Edicions UB.

DE CARLO, G. (1968). Planificacione e Disegno delle Università. Roma, Edicione Universitarie Italiane.

LERNER, J. (2005). Acupuntura urbana. Barcelona, laac.

MARTí, C. (2005). La cimbra y el arco. Barcelona, Fundación Caja de Arquitectos.

PERMANYER, L. (1995). 25 anys de la Universitat Politècnica de Catalunya i la història d'un territori. Lección inaugural del curso académico 1995-1996. Barcelona 26/09/1995.

ROCA, E.; LEZCANO, A. I FAYOS, R. (2009). Campus Diagonal. Un Projecte urbà. Barcelona, Edicions UB.

ROWE, C i KOETTER, F. (1989). Ciudad collage. Barcelona, Gustavo Gili.

SOLÀ - MORALES, M. (2008). De cosas urbanas. Barcelona, Gustavo Gili.

TRILLO, J.L. (2002). Universidad y ciudad. Sevilla, Universidad de Sevilla. 